\title{
Simultaneous Analysis of Four Standards of The Herbal Formula, DF-02, of Ephedra intermedia and Rheum palmatum, using by High Performance Liquid Chromatography-Ultraviolet Detector (HPLC-UVD)
}

\author{
Seong Yeon Choi ${ }^{1}$, Birang Jeong ${ }^{1}$, Hyeon Seok Jang ${ }^{1}$, Jiho Lee ${ }^{1}$, Yong Soo Kwon ${ }^{1}$, Yoosik Yoon ${ }^{2}$, \\ Soon Shik Shin ${ }^{3}$, and Heejung Yang ${ }^{1, *}$ \\ ${ }^{1}$ College of Pharmacy, Kangwon National University, Chuncheon 24341, Korea \\ ${ }^{2}$ Department of Microbiology, College of Medicine, Chung-Ang University, Seoul 06974, Korea \\ ${ }^{3}$ Department of Formula Sciences, College of Korean Medicine, Dong-Eui University, Busan 47227, Korea
}

\begin{abstract}
The herbal formula, DF-02, consisting of Ephedra intermedia and Rheum palmatum are used for the treatment of the metabolic diseases such as obesity and liver fibrosis in Korean local clinics. We aimed to develop the simultaneous analytical conditions for four standards, $(+)$-pseudoephedrine (PSEP) and (-)-ephedrine (EP) for E. intermedia, and aloe-emodin (AE) and chrysophanol (CP) for $R$. palmatum using HPLC-UV techniques. The validated conditions yielded the high precision (relative standard deviation (RSD) $<3.65 \%$ ) and the recoveries $(94-106 \%)$ using the calibration curves with high linearity $\left(R^{2}>0.9994\right)$. As a result, four standards of DF-02 were simultaneously determined under the developed method, which will be utilized for the quality control or evaluation of DF-02 and many herbal preparations containing E. intermedia and R. palmatum. Keywords - Ephedra intermedia, Rheum palmatum, (+)-pseudoephedrine, (-)-ephedrine, aloe-emodin, chrysophanol, HPLC, validation
\end{abstract}

\section{Introduction}

The herbal formula, DF-02, comprised of two traditional medicinal herbs, Ephedra intermedia Schrenk and Rheum palmatum Linne and is currently being used for the treatment of diabetes, obesity and the metabolic diseases in local Korean oriental medicine clinics. ${ }^{1}$ E. intermedia is one of Ephedra spp. native to Northeastern China, Russia, and Mongolia and has been used for the treatment of asthma and cough in Eastern Asia for a long time. ${ }^{2}$ Ephedra spp. have ephedra alkaloids such as (+)-pseudoephedrine (PSEP), $(-)$-ephedrine (EP), (+)-norpseudoephedrine and (-)norephedrine which are pharmacologically sympathomimetic agonists acting on both $\alpha$ - and $\beta$-adrenergic receptors. ${ }^{3,4}$ Recently the CNS stimulatory action of Ephedra spp. has been suggested as the therapeutic agents for the treatment of obesity. ${ }^{5}$. palmatum, a perennial plant, are used for purgation and purging heat, promote blood circulation and remove blood stasis in East Asian countries for a long time. ${ }^{6,7}$ Anthraquinone derivatives, such as emodin,

\footnotetext{
*Author for correspondence

Heejung Yang, Ph.D., College of Pharmacy, Kangwon National

University, Chuncheon 24341, Korea

Tel: +82-33-250-6919; E-mail: heejyang@kangwon.ac.kr
}

aloe-emodin (AE), chrysophanol (CP) and physcion, are the pharmacologically active components as naturally occurring laxatives of $R$. palmatum. In this study, we developed the simultaneous analytical method and validation of four standards, PSEP, EP, AE and CP, (Fig. 1) in DF-02 formula.

\section{Experimental}

Chemicals - PSEP and EP were gifted from Dr. Sang Hyun Sung, a professor of College of Pharmacy, Seoul National University. AE, CR and sodium dodecyl sulfate (SDS) were purchased from Sigma-Aldrich (St. Louis, MO, USA) and HPLC-grade water and acetonitrile from TEDIA (Fairfield, OH, USA).

Plant materials - The air-dried plants, E. intermedia $(1 \mathrm{~kg})$ and $R$. palmatum $(1 \mathrm{~kg})$, were provided from Dr. Soon Shik Shin, a professor of the Department of Korean medicine, Dong-eui University and identified by Dr. Yong Soo Kwon, a professor of College of Pharmacy, Kangwon National University. Two herbs were deposited in the Herbarium of College of Pharmacy, Kangwon National University (KNUPH-EI-1 and KNUPH-RP-1). 
Extraction of DF-02 formula - DF-02 formula was prepared by the patented technologies. Brifely, two herbs $E$. intermedia and $R$. palmatum were cut to $2-3 \mathrm{~cm}$, proportionally combined and mixed in the proportion of 9 (E. intermedia) and 1 (R. palmatum). The mixture was soaked $30 \%$ ethanol and extracted $(3 \times 3 \mathrm{~h})$ using Soxhlet technique at $85^{\circ} \mathrm{C}$. The mixture was then filtered and evaporated to dryness using a rotary evaporator. After freeze-drying to a powder $(20 \mathrm{mg})$, it was dissolved in 1 $\mathrm{mL}$ of $70 \%$ methanol for the analyses. All the samples were filtered through a $0.45 \mu \mathrm{m}$ polyvinylidene fluoride membrane filter before injection into a high performance liquid chromatography (HPLC).

Chromatographic conditions-HPLC system was carried out on Agilent 1260 Infinity system consisting of 1260 quaternary pump, autosampler and multiple wavelength detector (Agilent Technologies Mfg GmbH\&Co.KG, Waldbronn, Germany) and a Hector-M C18-M51002546 column $(250 \mathrm{~mm} \times 4.6 \mathrm{~mm} ; 5 \mu \mathrm{m}$, RStech, Daejeon, Korea), and all chromatograms were measured at $210 \mathrm{~nm}$ and $254 \mathrm{~nm}$ with the mixtures of HPLC-grade $\mathrm{H}_{2} \mathrm{O}$ buffered with $25 \mathrm{mM}$ SDS (solvent A) and acetonitrile (solvent B) at $30{ }^{\circ} \mathrm{C}$ temperature. The gradient elution condition was $60 \%$ solvent A $(0-25 \mathrm{~min})$ and $60-40 \%$ solvent A (25 - $35 \mathrm{~min})$ and $40 \%$ solvent A (35 - $40 \mathrm{~min})$ and $40-20 \%$ solvent A (40 - $50 \mathrm{~min}$ ) and $20 \%$ solvent A (50-60 min) with the flow rate of $1.0 \mathrm{~mL} / \mathrm{min}$, and aliquots of $10 \mu \mathrm{L}$ were injected using the autosampler for the analyses.

Method validation - The validation was performed in terms of linearity, limit of detection (LOD), limit of quantitation (LOQ), precision and accuracy were using the software (OpenLAB CDS ChemStation Edition1260 HPLC) according to the ICH guide line. To demonstrate the linearity, PSEP $(10,25,50,100$ and 250 $\mu \mathrm{g} / \mathrm{mL})$, EP $(25,100,250,500$ and $1000 \mu \mathrm{g} / \mathrm{mL}), A E(1$, $5,10,25$ and $250 \mu \mathrm{g} / \mathrm{mL})$ and $\mathrm{CP}(0.5,2.5,12.5,25$ and $250 \mu \mathrm{g} / \mathrm{mL}$ ) were respectively prepared based on the content of standard compounds in DF-02 formula. The linearity was measured through correlation coefficients $\left(\mathrm{R}^{2}\right)$. LOD and LOQ were calculated by the formula, $3.3 \times(\partial / \mathrm{S})$ and $10 \times(\partial / \mathrm{S})$, respectively. Herein, $\partial$ is the standard deviation of the $y$-axis value of the linear equation of the calibration curve and $\mathrm{S}$ is the slope value of the linear equation of the calibration curve. For the precision results, intra-day and inter-day tests were performed under the optimized HPLC analytical method. The recovery test was used to investigate the accuracy of this analysis method, the standard solutions with three different concentrations (PSEP (50, 100 and $250 \mu \mathrm{g} / \mathrm{mL}$ ),<smiles>CN[C@@H](C)[C@H](O)c1ccccc1</smiles>

1

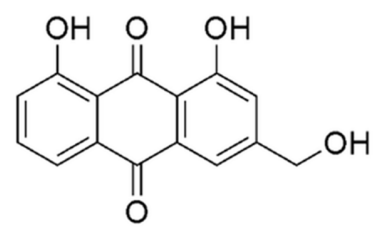

3<smiles>CN[C@@H](C)[C@H](O)c1ccccc1</smiles>

2

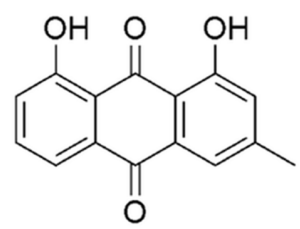

4
Fig. 1. The structures of (+)-pseudoephedrine (1), (-)-ephedrine (2), aloe-emodin (3) and chrysophanol (4).

EP $(500,750$ and $1000 \mu \mathrm{g} / \mathrm{mL}), \operatorname{AE}(2,5$ and $10 \mu \mathrm{g} / \mathrm{mL})$ and CP $(0.5,2.5$ and $12.5 \mu \mathrm{g} / \mathrm{mL})$ ) were added to DF-02 formula dissolved in $100 \% \mathrm{MeOH}(20 \mathrm{mg} / \mathrm{mL})$ and analyzed in triplicate. And these three different concentration solutions (added PSEP, EP, AE and CP) were used to intra-day and inter-day tests. The intra-day test of four compounds were tested in three different concentrations within 1 day and the inter-day test were conducted over 3 days (first, third and fifth day), respectively. The relative standard deviation (RSD) was taken as a measure of repeatability.

\section{Results and Discussion}

PSEP and EP for E. intermedia, and $\mathrm{AE}$ and $\mathrm{CP}$ for $R$. palmatum were known as the major constituents with the pharmacological activities for each herb and were applied as the maker compounds to validate DF-02 formula which were perepared with two herbs (Fig. 1). Because PSEP and EP are alkaloid-type compounds with a secondary amine group and are positively charged, the acidic buffers, such as formic acid and phosphric acid, were applied to form netural ion pair complexes for the better separation. Among the buffer system, the solvent system buffered with $25 \mathrm{mM}$ SDS was found to be suitable for reproducibility in routine analysis, without the deterioration of peaks for PSEP and EP in the previous studies. ${ }^{8}$ Also the solvent system buffered with SDS was suitable for the chromatographic separation of less polar compounds, $\mathrm{AE}$ and $\mathrm{CP}$, in the column (Fig. 2). In the optimized solvent condition, four standards, AE, PSEP, EP and CP were detected at 16.9, 27.3, 29.1 and 47.5 


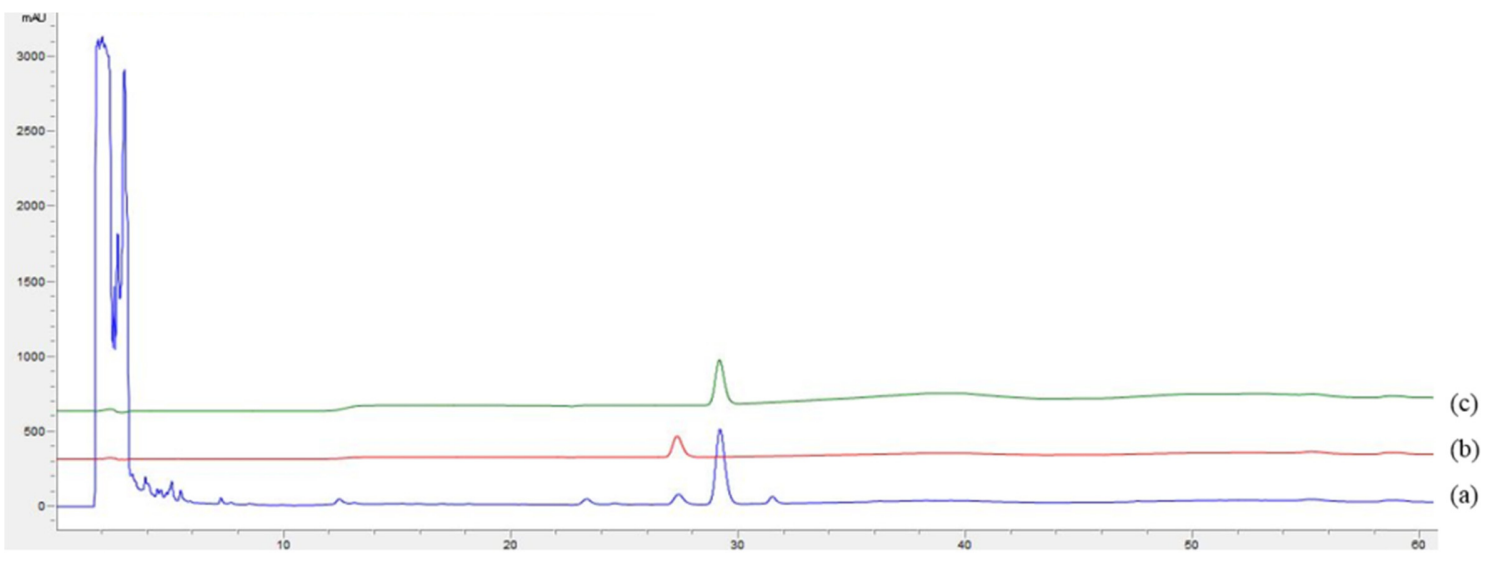

(A)

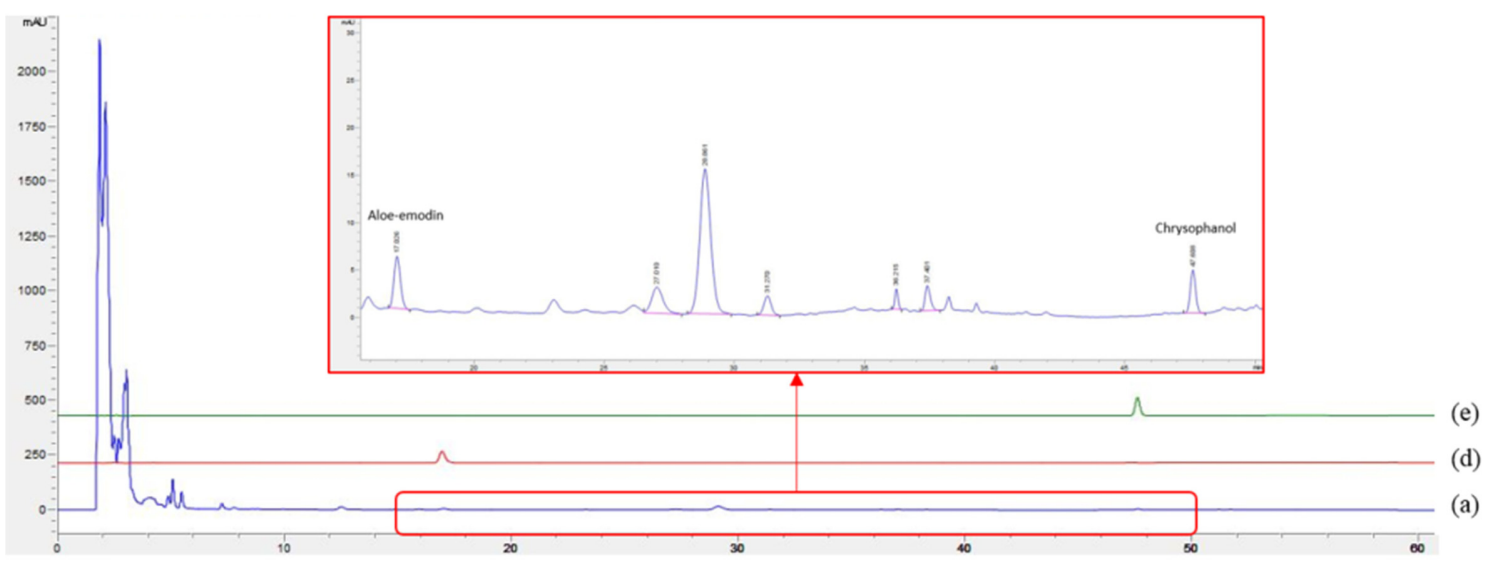

(B)

Fig. 2. HPLC chromatogram of DF-02 formula and the standards obtained at UV 210 (A) and 254 (B) nm: (a) DF-02 formula (20 mg/ $\mathrm{mL})$, (b) (+)-pseudoephedrine, (c) (-)-ephedrine, (d) aloe-emodin and (e) chrysophanol. Detailed experimental conditions are described in the Experimental section.

Table 1. The linear regression curves, LODs and LOQs of four standards.

\begin{tabular}{cccccc}
\hline \hline Compounds & Retention time & Linear regression equation & $\mathrm{R}^{2}$ & $\mathrm{LOD}(\mu \mathrm{g} / \mathrm{mL})$ & $\mathrm{LOQ}(\mu \mathrm{g} / \mathrm{mL})$ \\
\hline PSEP $^{\mathrm{a}}$ & 27.3 & $\mathrm{y}=16514 \mathrm{x}+43.426$ & 0.9994 & 0.0006 & 0.0017 \\
$\mathrm{EP}$ & 29.1 & $\mathrm{y}=16857 \mathrm{x}-39.23$ & 1.0000 & 0.0060 & 0.0181 \\
$\mathrm{AE}$ & 16.9 & $\mathrm{y}=39616 \mathrm{x}+32.922$ & 1.0000 & 0.0036 & 0.0107 \\
$\mathrm{CP}$ & 47.5 & $\mathrm{y}=38598 \mathrm{x}+19.515$ & 1.0000 & 0.0007 & 0.0022 \\
\hline
\end{tabular}

a PSEP: (+)-pseudoephedrine, EP: (-)-ephedrine, AE: aloe-emodin, CP: chrysophanol

min, respectively.

The calibration curves for four standards showed the good linearity with high correlation coefficients $\left(\mathrm{R}^{2}=\right.$ $0.9994)$, and the LOD and LOQ values were in the range of $0.6 \sim 3.6 \mathrm{ng} / \mathrm{mL}$ and $1.7 \sim 10.7 \mathrm{ng} / \mathrm{mL}$, respectively (Table 1). SDS has a negative ion allowing to form neutral ion pair complexes with a positive ion of EP and PSEP. Also, the $\mathrm{AE}$ and $\mathrm{CP}$ standards were well retained and give higher resolution in the column. The low quantity of $R$. palmatum in DF-02 formula and low extraction efficiency of less-polar $\mathrm{AE}$ and $\mathrm{CP}$ under 30\% EtOH solvent hindered the detection of AE and CP in DF-02 formula at $210 \mathrm{~nm}$, but they were simultaneously detected at $254 \mathrm{~nm}$ using multi-channel function of UV detector. (Fig. 2) As a result, the optimized analytical condition was applied to the further validation study. The precision of the optimized analytical methods was confirmed by RSDs of less than $2.53 \%$ for the intra-day and $3.65 \%$ for the inter-day tests. Also, four standards were well-recovered with high yields of $94.3 \sim 106.2 \%$, respectively. (Table 2) Under the optimized 
Table 2. Precision and accuracy test of four standards

\begin{tabular}{|c|c|c|c|c|c|c|c|}
\hline \multirow{3}{*}{ Compounds } & \multicolumn{4}{|c|}{ Precision } & \multicolumn{3}{|c|}{ Accuracy } \\
\hline & \multicolumn{2}{|c|}{ Intra-day } & \multicolumn{2}{|c|}{ Inter-day } & \multirow{2}{*}{$\begin{array}{l}\text { Spiked amount } \\
\text { (mg/g) }\end{array}$} & \multirow{2}{*}{ Accuracy (\%) } & \multirow{2}{*}{ RSD (\%) } \\
\hline & Amount (mg/g) & RSD (\%) & Amount (mg/g) & RSD (\%) & & & \\
\hline \multirow{3}{*}{ PSEP $^{\mathrm{a}}$} & 4.42 & 0.91 & 4.45 & 0.89 & 4.28 & 103.26 & 0.91 \\
\hline & 5.79 & 0.99 & 5.74 & 2.60 & 5.65 & 102.46 & 0.99 \\
\hline & 9.56 & 0.19 & 9.51 & 2.05 & 9.26 & 103.27 & 0.19 \\
\hline \multirow{3}{*}{$\mathrm{EP}$} & 35.85 & 0.85 & 35.48 & 3.01 & 33.77 & 106.16 & 0.85 \\
\hline & 39.94 & 1.35 & 39.72 & 0.49 & 39.97 & 99.93 & 1.35 \\
\hline & 47.50 & 0.39 & 45.64 & 3.65 & 46.21 & 102.79 & 0.39 \\
\hline \multirow{3}{*}{$\mathrm{AE}$} & 0.07 & 2.531 & 0.07 & 0.14 & 0.07 & 99.64 & 2.53 \\
\hline & 0.17 & 1.79 & 0.18 & 2.02 & 0.17 & 102.54 & 1.79 \\
\hline & 0.29 & 2.40 & 0.30 & 1.47 & 0.30 & 98.36 & 2.40 \\
\hline \multirow{3}{*}{$\mathrm{CP}$} & 0.03 & 1.03 & 0.03 & 3.38 & 0.03 & 105.30 & 1.03 \\
\hline & 0.08 & 2.17 & 0.08 & 1.19 & 0.08 & 94.33 & 2.17 \\
\hline & 0.35 & 0.43 & 0.34 & 2.88 & 0.34 & 102.62 & 0.43 \\
\hline
\end{tabular}

a PSEP: (+)-pseudoephedrine, EP: (-)-ephedrine, AE: aloe-emodin, CP: chrysophanol

analytical conditions, the contents of four standards in DF-02 formula were determined as $6.09 \mathrm{mg} / \mathrm{g}$ for PSEP, $42.91 \mathrm{mg} / \mathrm{g}$ for $\mathrm{EP}, 0.11 \mathrm{mg} / \mathrm{g}$ for $\mathrm{AE}$ and $0.06 \mathrm{mg} / \mathrm{g}$ for $\mathrm{CP}$, respectively. In this study, we successfully established the simultaneous determination method of four chemical markers, EP, PSEP, AE and CP, of DF-02 formula consisting of $E$. intermedia and $R$. palmatum.

\section{Acknowledgments}

This research was supported by a grant of the Korea Health Technology R\&D Project through the Korea Health Industry Development Institute (KHIDI), funded by the Ministry of Health \& Welfare, Republic of Korea (No. HI15C0075).

\section{References}

(1) Jeong, B.; Choi, S. Y.; Jang, H. S.; Yoo, G.; Kim, S. H.; Kim, J.; Kwon, Y. S.; Roh, J. S.; Yoon, Y.; Shin, S. S. Nat. Prod. Sci. 2017, 23, 915.

(2) Kee, C. H. The Pharmacology of Chinese Herbs; CRC Press: U.S.A., 1999, p 308.

(3) Yamada, I.; Goto, T.; Takeuchi, S.; Ohshima, S.; Yoneyama, K.; Shibuya, T.; Kataoka, E.; Segawa, D.; Sato, W.; Dohmen, T.; Anezaki, Y.; Ishii, H.; Ohnishi, H. Cytokine. 2008, 41, 293-301.

(4) Ma, G.; Bavadekar, S. A.; Davis, Y. M.; Lalchandani, S. G.; Nagmani, R.; Schaneberg, B. T.; Khan, I. A.; Feller, D. R. J. Pharmacol. Exp. Ther. 2007, 322, 214-221.

(5) Fleming, R. M. Expert Opin. Drug Saf. 2008, 7, 749-759.

(6) Chen, D. C.; Wang, L. Chin. J. Traumatol. 2009, 12, 365-369.

(7) Barceloux, D. G. Dis. Mon. 2009, 55, 403-411.

(8) Sheu, S.; Huang, M. J. Food Drug Anal. 2000, 8, 337-341.

Received November 11, 2018

Revised December 9, 2018

Accepted December 9, 2018 